The most urgent phase in diagnosis is recognition of hypoglycaemia as the cause of coma or of bizarre neurological signs, particularly when these occur in a wasted patient with a history of alcoholism or alcohol in the breath. These features should alert the doctor to the chance of the condition, and he should estimate the level of blood glucose (initially by Dextrostix). A therapeutic trial of intravenous glucose may be justified. Hypothermia ${ }^{10}$ and trismus ${ }^{12}$ are nonspecific signs that may accompany alcoholic hypoglycaemia.

Alcohol is more likely to be the cause of hypoglycaemic episodes if there is a history of taking drink before the attacks, an absence of attacks during abstinence, and if hypoglycaemia can be induced by infusion of alcohol after an 18-hour fast. An insulinoma may mimic alcoholic hypoglycaemia, and the response of the level of blood sugar to fasting, tolbutamide, and leucine may give identical results in both instances. Measurement of plasma insulin levels in response to tolbutamide and leucine should help distinguish these conditions, since most patients with insulinoma show an excessive rise in response to tolbutamide or leucine, ${ }^{11}$ whereas levels are low in alcoholic hypoglycaemia. ${ }^{3} 12$

Hypoglycaemia due to deficiency of A.C.T.H. can be precipitated by alcohol, ${ }^{13}$ but it should be diagnosed correctly by assessment of adrenal and pituitary function.

\section{Medical Social Work in General Practice}

When the N.H.S. was framed it was assumed that medical practice was mainly about organic disease, with social and emotional factors playing little part. There might be a place in a large hospital for a social worker but not in general practice. The general practitioner, traditional adviser on non-medical matters, though trained only for clinical ones, and the health visitor, whom he seldom saw, would no doubt cope with all social problems.

Ten years later E. M. Backett, R. P. Maybin, and Yvonne Dudgeon $^{1}$ described the need for a social worker in general practice. In 1962 the Porritt Committee ${ }^{2}$ suggested that medical social workers in the community services were a necessity, though Joan Collins, ${ }^{3}$ describing in 1965 her attachment to a group practice in Cardiff, doubted whether they should be attached to every general practice. Before a medical social worker could be at home in the surgery something would need to change in the doctor-patient relationship, she thought, so that the doctor could make an effective assessment of the patient's whole need and the patient regard the doctor as more than a provider of medical care.

Now J. A. S. Forman and E. M. Fairbairn describe the experimental attachment of a medical social worker to a large group practice for three years. They show that the doctor-patient relationship can be adapted to this arrangement. Once the general practitioners had appreciated the medical social worker's capabilities and limitations and she had assimilated the content and methods of their work, effective communication was established at

Backett, E. M., Maybin, R. P., and Dudgeon, Y., Lancet, 1957, 1, 37. - Porritt, Sir A. (1962). Reviez of Medical Services in Great Britain.

- Collins, Joan, Social Casework in a General Medical Practice. 1965. London.

- Forman, J. A. S., and Fairbairn, E. M., Social Casework in General Practice. 1968. Published by Nuffield Provincial Hospital Trust by Oxford University Press (pp. viii +118 ; 12s. 6d. net).

- Health Centres and Group Practices, 1966. British Medical Association. regular meetings. The doctor-patient relationship was enlarged and strengthened by including the medical social worker. Her function was to assess the family's total situation and help the patient to define his problems, find solutions, and, where situations are unalterable, support him. She became a personal social worker in a way that a traditional social worker could never do, if only because many patients are reluctant to discuss personal problems with an outsider. They accepted her, as they accepted their own doctor's partners, as part of the practice team and trusted her to see them through socially as he saw them through medically, co-ordinating outside social agencies as he co-ordinated outside medical ones. Her work was not mainly with psychotic patients or problem families; rather it was with people normally able to cope but temporarily disabled by illness and emotional and social reactions to it. She improved the service the practice as a whole was able to give in ways whose importance is often underestimated.

The special relationship of the family doctor to his patients gives ready access to them by associates working closely with him. Ideally one of these should be a medical social worker. She can help to make the work of the practice both easier and more effectual, ${ }^{5}$ thereby contributing also to make it a "worthwhile career," on which Dr. J. C. Cameron writes in our correspondence columns at page 506. But since there are too few medical social workers the middle grade of social worker, whose new two-year training course emphasizes understanding of people, might be an adequate substitute. She would help even patients with complex problems to understand them, enabling them to use the service of highly trained medical social workers in a consultant role, and by recognizing deteriorating situations before they reached crisis point could fill a much-needed preventive role in the community.

\section{Wrist-watch Tinea}

A red scaling and itching eruption often develops in the area of skin on the back of the wrist immediately beneath the wrist watch. In most cases this is caused by a contact allergic sensitivity to the metal of the watch usually due to nickel or more rarely to chrome. This is commonly part of a general sensitivity, and other sites in contact with metal may be affected. In a few cases the wrist-watch strap is responsible, but the eruption in these cases is likely to affect the whole area of contact with the strap.

Another possible cause of an eruption developing beneath the wrist watch is an infection with a ringworm fungus or, rarely, with candida. Recently $H$. E. Kleine-Natrop ${ }^{1}$ has drawn attention to this and described three patients all of whom had Trichophyton rubrum infection. Other ringworm fungi can also cause the condition, including Epidermophyton floccosum, and in these patients evidence of a primary ringworm infection elsewhere is likely to be found.

The clinical differential diagnosis may be difficult, but Kleine-Natrop points to several features in the develcpment and appearance of ringworm infection that help to distinguish it from a sensitivity reaction. In particular, ringworm tends to start in one small area beneath the watch, it then spreads gradually, and the final area affected may not exactly correspond with the watch site. If there is doubt mycological examination of scrapings will give the correct diagnosis.

\footnotetext{
1 Kleine-Natrop, H. E., Germ. med. Mth, 1967, $12,598$.
} 